\title{
Correction to: Late Presentation of HIV Infection in the Netherlands: Reasons for Late Diagnoses and Impact on Vocational Functioning
}

\author{
S. E. M. van Opstal ${ }^{1,3}$ - J. S. van der Zwan ${ }^{1}$ - M. N. Wagener ${ }^{1}$ - S. K. Been ${ }^{2} \cdot$ H. S. Miedema ${ }^{1}$ • P. D. D. M. Roelofs ${ }^{1}$. \\ E. C. M. van Gorp ${ }^{3}$
}

Published online: 24 August 2018

(c) The Author(s) 2018

\section{Correction to: AIDS and Behavior (2018) 22:2593-2603 https://doi.org/10.1007/s10461-018-2082-9}

The original version of this article was published open access. Unfortunately, due to a technical issue, the copyright holder name in the online version (HTML and XML) is incorrectly published as "Springer Science + Business Media, LLC, part of Springer Nature 2018". Instead, it should be "The Author(s) 2018".

The original article has been corrected.

\begin{abstract}
Open Access This article is distributed under the terms of the Creative Commons Attribution 4.0 International License (http://creativecommons.org/licenses/by/4.0/), which permits unrestricted use, distribution, and reproduction in any medium, provided you give appropriate credit to the original author(s) and the source, provide a link to the Creative Commons license, and indicate if changes were made.
\end{abstract}

The original article can be found online at https://doi.org/10.1007/ s10461-018-2082-9.

S. E. M. van Opstal

s.e.m.van.opstal@hr.nl

1 Center of Expertise Innovations in Care, Rotterdam University of Applied Sciences, Rochussenstraat 198, 3015 EK Rotterdam, The Netherlands

2 Erasmus MC, Department of Internal Medicine and Infectious Diseases, University Medical Center Rotterdam, Rotterdam, The Netherlands

3 Erasmus MC, Department of Viroscience, University Medical Center Rotterdam, Rotterdam, The Netherlands 